\title{
AS RESTRIÇÕES À ANÁLISE DO MÉRITO NAS CONVENÇÕES COLETIVAS DE TRABALHO DECORRENTES DA LEI $13.467 / 2017^{*}$
}

\author{
Eduardo Soares de Oliveira** \\ Almiro Eduardo de Almeida***
}

\section{RESUMO}

O presente artigo teve como objetivo analisar as mudanças trazidas para a legislação trabalhista após a aprovação da Lei 13.467/2017, conhecida como reforma trabalhista, no que tange a análise de mérito dos julgadores em relação as negociações coletivas de trabalho, mais precisamente nas alterações ao artigo 8o e o acréscimo do artigo 611-A na Consolidação das Leis Trabalhistas (CLT). Neste contexto, o trabalho procurou observar possíveis violações de direitos humanos nessas alterações legislativas. Primeiramente, buscou traçar um resumo da evolução histórica dos direitos humanos e fundamentais, sua conceituação e relação com o ordenamento jurídico brasileiro, mediante síntese histórica e traçando linhas gerais sobre os organismos internacionais que os salvaguardam. Em um segundo momento, analisou a constitucionalidade dos artigos referidos, por meio de bibliografia relacionada ao tema, e ao final são tecidas algumas considerações acerca dessas mudanças e aos possíveis retrocessos que ela pode gerar.

Palavras-chave: Direitos humanos. Direitos Fundamentais. Direito Coletivo do Trabalho. Reforma Trabalhista.

* Trabalho de Conclusão de Curso apresentando ao Curso de Direito do Centro Universitário Metodista - IPA, na área de concentração do Direito do Trabalho como requisito parcial para obtenção do grau de Bacharel em Direito.

** Graduando do curso de graduação em Direito do Centro Universitário Metodista - IPA

*** Orientador do artigo, Doutor em Direito do Trabalho, Juiz do Trabalho e professor do Curso de Bacharelado em Direito do Centro Universitário Metodista - IPA. 


\section{THE RESTRICTIONS TO THE ANALYSIS OF MERIT IN THE COLLECTIVE LABOR CONVENTIONS ARISING FROM LAW 13.467 / 2017}

\section{ABSTRACT}

The purpose of this article was to analyze the changes brought to labor legislation after the approval of Law 13.467/2017, known as labor reform, regarding the analysis of the merits of the judges in relation to collective negotiations, more precisely at changes in the article 8th and the article 611-A addition in the Consolidation of Labor Laws (CLT). In this context, the paper sought to observe possible violations of human rights in these legislative changes, first, pursue to outline the historical evolution of human and fundamental rights, its conceptualization and relation with Brazilian legal system, by historical synthesis and outlining the international organizations that safeguard them. In a second moment, it analyzed the constitutionality of the mentioned articles, through bibliography related to the subject, and at the end are made some considerations about these changes and the possible setbacks that it can be generated.

Keywords: Human rights. Fundamental rights. Collective Labor Law. Labor Reform.

\section{INTRODUÇÃO}

0 presente trabalho procura apresentar o tema da reforma trabalhista, em relação às mudanças na análise de mérito nas negociações coletivas e os direitos humanos fundamentais, imprescindíveis para uma vida harmoniosa em sociedade.

O problema de pesquisa que norteia o presente trabalho é o seguinte: se estas mudanças caracterizam ofensa aos direitos humanos dos trabalhadores?

Toda mudança realizada no ordenamento jurídico pátrio deve ser pautada nos princípios existentes na Constituição Federal e ainda sempre respeitar os tratados internacionais de direitos humanos que o Brasil seja signatário. Deste modo, quaisquer mudanças devem preceder de uma análise criteriosa pelo legislador para evitar redução ou cerceamento de direitos fundamentais e, mesmo após sua aprovação, poderá ser objeto de 
debate no Poder Judiciário através dos mecanismos de controle de constitucionalidade.

0 Projeto de Lei $n^{\circ} 6.787$ de 2016 foi apresentado pelo poder executivo em 23 de dezembro de 2016 e teve tramitação recorde, sendo aprovada pela Câmara dos Deputados e o Senado Federal e sancionada pelo Poder Executivo em seis meses, tais mudanças careceram de um debate mais profundo com a sociedade. A título de exemplo, o projeto de lei $n^{\circ} 634$ de 1975 propunha o texto do novo código civil brasileiro, que seria transformado na lei $\mathrm{n}^{\circ}$ 10.406 somente em 2002.

As restrições à análise do mérito nas convenções coletivas de trabalho previstas na lei ${ }^{\circ} 13.467$ de 2017 que deu nova redação ao Decreto-lei n5.452 de $1^{\circ}$ de maio de 1943 (Consolidação das Leis do Trabalho - CLT) nos leva a um debate necessário sobre tais mudanças na legislação e o impacto disso nos direitos humanos fundamentais dos trabalhadores.

As alterações legislativas sempre provocam mudanças na sociedade, principalmente, as que envolvem direitos trabalhistas, por alcançarem grandes parcelas da população; sendo que, as relações de trabalho, em uma sociedade capitalista, são as mais importantes para a manutenção da dignidade humana e estão, diretamente, relacionadas com os direitos fundamentais previstos na Constituição e com o sistema internacional de direitos humanos.

O panorama geral do país que levou a elaboração e aprovação destas mudanças na legislação do trabalho foi de grave crise econômica 0 projeto de lei $6.787 / 2016$, em sua propositura justifica essas alterações objetivando maior segurança jurídica, respeito a autonomia coletiva da vontade e o fortalecimento da estrutura sindical permitindo assim a expansão das condições de negociação dos sindicatos diante das rígidas regras da CLT ${ }^{1}$.

BRASIL. Decreto-Lei no 5.452 de 1o de maio de 1943 (Consolidação das Leis Trabalhistas) - Diário Oficial [da] República Federativa do Brasil. Poder Executivo, Brasília, DF, 09 de Agosto de 1943 
Sobre esse momento vivido pelo pais nos esclarece Mauricio Godinho Delgado.

\begin{abstract}
A reforma trabalhista prevista na Lei $n$. 13.476/2017 reforça vertente ideológica impulsionada na década de 1990, no Brasil, de desregulamentação dos direitos sociais e de flexibilização acentuada das relações de trabalho, ao prever, em diversos de seus dispositivos, mecanismos de supressão ou de redução do patamar de proteção social e de acentuada desarticulação dos direitos e garantias fundamentais trabalhistas ${ }^{2}$.
\end{abstract}

Neste contexto foram aprovadas inúmeras flexibilizações na norma trabalhista. Uma dessas mudanças que será o objeto de análise deste trabalho é a prevista no artigo $8^{\circ} \S 3$ da CLT.

\begin{abstract}
No exame da convenção coletiva ou acordo coletivo de trabalho, a Justiça do Trabalho analisará exclusivamente a conformidade dos elementos essenciais do negócio jurídico respeitando o disposto no art. 104 da lei $n^{\circ} 10.406$ de 12 de janeiro de 2002 (código civil) e balizará sua atuação pelo princípio da intervenção mínima na autonomia da vontade. (grifo nosso) ${ }^{3}$ :
\end{abstract}

Dispõe ainda o artigo 611- $\mathrm{A}^{4}$ sobre as convenções coletivas: A convenção coletiva e o acordo coletivo têm prevalência sobre a lei quando, entre outros, dispuser sobre [...] (grifo nosso). É de fácil observação que esses dois artigos limitam o papel da Justiça do Trabalho na análise das negociações coletivas,

2 DELGADO, Mauricio Godinho. DELGADO, Gabriela Neves. A reforma trabalhista no Brasil: com os comentários à Lei n. 13.467/2017 São Paulo: LTr, 2017, p. 73

3 BRASIL. Lei n¹3.467 de 13 de julho de 2017 Diário Oficial [da] República Federativa do Brasil. Poder Executivo, Brasília, DF, 13 de julho de 2017 4 Ibidem. 
atingindo a parte hipossuficiente nas relações de trabalho, o empregado.

Deste modo esta limitação caracteriza ofensa aos direitos humanos dos trabalhadores. Logo, é iminente a necessidades de uma análise destas alterações ora expostas, pois ao serem aplicadas, poderão provocar perda ou diminuição dos direitos humanos e fundamentais dos trabalhadores.

Antes, contudo é preciso realizar uma breve síntese sobre o que são direitos humanos fundamentais, sua evolução histórica e seus avanços, e como esses direitos estão positivados na legislação pátria, para observar se essas mudanças são prejudiciais aos trabalhadores e se estes direitos, ora em possibilidade de supressão, podem ser considerados direitos humanos fundamentais.

O trabalho será dividido em capítulos, utilizando-se do método dedutivo e histórico bibliográfico, com apresentação de evoluções e conceitos gerais dos temas relacionados e, de maneira específica, demonstrar a contrariedade das alterações na negociação coletiva frente direitos fundamentais.

\section{DIREITOS HUMANOS: EVOLUÇÃO HISTÓRICA E CONCEITO}

Para tratar dos direitos humanos relacionados ao Direito do Trabalho, primeiramente, faz-se necessário evidenciar as principais fontes do ordenamento jurídico brasileiro e internacional na matéria trabalhista, quais sejam:

a) Constituição Federal

b) Consolidação das Leis Trabalhistas (CLT) e Código de Processo Civil (CPC)

C) Acordos e convenções coletivas

D) Convenções e Recomendações da Organização Internacional do Trabalho (OIT)

Como fonte principal do Direito do Trabalho no Brasil se tem a Constituição Federal de 1988 que, versa no capitulo 2 
onde enumera os direitos e garantias fundamentais, em especial o artigo $7^{\circ}$ que versa sobre os direitos dos trabalhadores

$\mathrm{Na}$ CLT, estão inseridas a maioria das garantias dadas ao empregado e empregador em uma relação de trabalho e o Código de Processo Civil - CPC, também utilizado de forma subsidiária naquilo que a CLT é omissa (Art. 796 da CLT).

Ademais, muito utilizado e com grande importância no Direito do Trabalho, os acordos e convenções coletivas (sentenças normativas) são grandes fontes de matérias relacionados ao cotidiano do trabalho.

Outrossim, no Direito Internacional do Trabalho as fontes de direitos se apresentam de várias formas, como em tratados, convenções e pactos firmados e ratificados por cada país. São em sua maioria formulados por entes públicos internacionais que possuem caráter independente e autônomo a qualquer Estado de Direito. No contexto internacional de direitos e deveres trabalhistas os entes públicos internacionais detêm competência para criar normas, fiscalizar e garantir direitos trabalhistas mínimos, como por exemplo, a Organização Internacional do Trabalho - OIT e o Sistema Interamericano de Direitos Humanos - SIDH.

As fontes de direito do trabalho provenientes dos tratados internacionais são qualificadas como normas supraconstitucionais, já que possuem especial colocação no ordenamento jurídico, estando correlacionado a própria norma constitucional.

Sendo assim, existem inúmeros direitos em relações provenientes do mundo do trabalho, tanto no plano internacional quanto no ordenamento interno, visando essencialmente garantir a dignidade do trabalhador em uma relação de trabalho que procure sempre a manutenção da paz social.

Para um melhor entendimento acerca do tema tratado, faz-se necessário um apanhado da evolução dos direitos ora chamados de fundamentais e humanos, pois, os direitos do homem antece- 
dem ao direito constitucional positivo do século XVIII, conforme ensinamentos de Ingo Wolfgang Sarlet:

Sintetizando o devir histórico dos direitos fundamentais até o seu reconhecimento das primeiras Constituições escritas, K. Stern, conhecido mestre de Colônia, destaca três etapas: a) uma pré-história, que se estende até o século XVI; b) uma fase intermediária, que corresponde ao período de elaboração da doutrina jus naturalista e da afirmação dos direitos naturais do homem; c) a fase de constitucionalização, iniciada em 1776, com excessivas declarações de direitos dos novos Estados americanos. ${ }^{5}$

Desta forma, é correto afirmar que a antiguidade foi responsável por delegar princípios e conceitos básicos que, posteriormente, viriam a ser chamados de direitos do homem ou fundamentais. Ainda, segundo Sarlet, foi de vital importância, por exemplo, já na era moderna, a reforma protestante, quando do reconhecimento da liberdade religiosa na Europa, foi um indicador para o surgimento dos direitos fundamentais ${ }^{6}$.

$\mathrm{O}$ atual patamar civilizatório das nações foi conquistado por meio de constante beligerância em momentos históricos de ampla tensão. esta provocada geralmente pela classe dominante que não aceitava a perda de seu status quo e ansiava pela manutenção de privilégios e poder.

Nesta esteira ocorreram momentos de ruptura com a organização social anteriormente estabelecida como a Revolução Francesa e a independência dos Estados Unidos da America no século XVIII; em um segundo momento já no século XIX o advento da sociedade capitalista industrial e a ampla exploração

5 SALET, Ingo Wolfgang. A eficácia dos direitos fundamentais - uma teoria geral dos direitos fundamentais na perspectiva constitucional.11aㅡ ed. rev. atual. Porto Alegre: Livraria do advogado, 2012. p 37;

$6 \quad$ Idem, pag.42 
da mão de obra levam a revoltas operarias e a necessidade de ordenamentos que garantissem que exploração do trabalho não causassem maléficos e destruí-se a própria sociedade.

Mas sem duvida, o maior momento de ruptura histórica, que obrigará as nações a pensar em direitos inerentes a condição humana e a positivá-los em ordenamentos internacionais foi o horror do holocausto provocado pelos movimentos totalitários nazi-fascistas na primeira metade do século XX, Assim, os países resolveram criar mecanismos para que aquelas atrocidades perpetuadas pelo ultra nacionalismo não voltassem a ocorrer.

\section{EVOLUÇÃO HISTÓRICA DOS DIREITOS HUMANOS}

Os direitos humanos apresentam-se ao longo da história, segundo Delgado em três momentos distintos: o da conscientização da existência de direitos naturais, evidentes à razão; o da positivação desses direitos no ordenamento constitucional; e, finalmente, o da efetivação dos direitos ${ }^{7}$.

Porém, apenas após as primeiras declarações de direitos e a Constituição Norte Americana é possível afirmar que os direitos fundamentais foram reconhecidos pelo direito positivo.

Os direitos humanos são identificados por gerações de direitos, onde os de primeira geração estão relacionados aos direitos de limitação do poder Estado, visando assim as liberdades civis e políticas do cidadão frente a um Estado autoritário.

Sobre esse primeiro período nos ensina Delgado

Os direitos civis, conquistados no século XVIII, fundamentam a concepção liberal clássica de direitos. Os políticos, oriundos do século XIX, referem-se à liberdade de associação e participação política, eleitoral e sindical Importantes exemplos de consti-

7 DELGADO, Mauricio Godinho. DELGADO, Gabriela Neves. A reforma trabalhista no Brasil: com os comentários à Lei n. 13.467/2017. São Paulo: LTr. 2017. p.63; ${ }^{11}$ IBID, p.63 - 64. 
tuições que exaltaram os direitos fundamentais de primeira geração são a Constituição Norte-Americana de 1787 e a Constituição Francesa de $1791^{11}$.

Neste período, no auge dos ideais de liberdade e igualdade, fundamentados no pensamento iluminista revelam-se os primeiros direitos relacionados ao mundo do trabalho ${ }^{8}$. Assim, em relação ao Direito do Trabalho nos ensina Norberto Bobbio:

Os direitos sociais sob forma de instituição da instrução pública e de medidas a favor do trabalho para os "pobres válidos que não puderam consegui-lo" fazem a sua primeira aparição no título I da Constituição Francesa de 1791 e são solenemente nos artigos 21 e 22 da declaração de junho de $1793 .{ }^{9}$

Após este primeiro período de afirmação dos direitos civis, passam-se a novas necessidades. As mudanças na sociedade e nos meios de trabalho e a afirmação do modelo capitalista fizeram com que fossem necessários a conquista de mais direitos, deste modo advém os chamados direitos de segunda geração, que são os direitos sociais, como nos ensina o saudoso Ministro Teori Zavaski

Modelado à base dessa segunda geração de direitos fundamentais, nasceu o chamado Estado do bem-estar social. E, assim, o século XX foi todo ele dominado pela força propulsora dos direitos fundamentais inspirados na igualdade. Não há estatuto jurídico, no atual estágio de nosso direito ocidental, que não contenha pautas de reconhecimento explícito de direitos

8 Declaração Universal dos Direitos do Homem de 1793 - Artigo 21: "os auxílios públicos são uma dívida sagrada. A sociedade deve a subsistência aos cidadãos infelizes, quer seja procurando-lhes trabalho, quer seja assegurando os meios de existência àqueles que são impossibilitados de trabalhar" / Artigo 22 "a instrução é a necessidade de todos. A sociedade deve favorecer tom todo o seu poder o progresso da inteligência pública e colocar a instrução ao alcance de todos os cidadãos"

9 BOBBIO, Norberto. A era dos direitos: tradução de Carlos Nelson Coutinho. $10^{\circ}$ reimpressão. Ed. 
desta natureza igualitária [...]Os Estados, outrora omissos, agora proclamam compromissos solenes de estabelecer políticas públicas destinadas a eliminar desigualdades sociais e de promover, em todos os seus aspectos, a dignidade da pessoa humana. ${ }^{14}$

Segundo Delgado neste período, destacam-se o surgimento das primeiras Constituições Sociais: a constituição mexicana de 1917 e a constituição de Weimar na Alemanha em 1919 foram pioneiras na constitucionalização dos direitos de segunda geração e na afirmação do Estado Social ${ }^{15}$.

Já na era contemporânea, após a Segunda Guerra Mundial, com o Estado Democrático de Direito é possível falar nos direitos de terceira geração, relacionados aos direitos de fraternidade e solidariedade, e após a Declaração Universal dos Direitos Humanos de $1948^{16}$ sobre uma universalização dos direitos.

Sobre este período nos ensina Mauricio Godinho Delgado que esses direitos são de carater difusos, relacionados com um viés de coletividade, marcados pelo humanismo caracterizados por contemplaram os direitos atribuídos a toda a sociedade, como o direito a paz, ao meio ambiente a auto determinação dos povos, entre outros ${ }^{17}$.

Hodiernamente é possível afirmar a existência de direitos de quarta geração, que segundo Eliana Calmon são relacionados a qualidade de vida e o respeito a biodiversidade, deste modo se faz necessário ordenar e disciplinar o espaço físico e o meio-ambiente ${ }^{10}$.

Paulo Bonavides, afirma a existência de uma quinta geração de direitos relacionada com o próprio direito a paz destacando a importância para o seu reconhecimento jurídico e sua integração para a compreensão da democracia, legitimando o estabelecimento da ordem, da liberdade e do bem comum na convivência dos povos ${ }^{11}$.

10 ALVES, Eliana Calmon. Direitos de quarta geração: biodiversidade e biopirataria. Revista do Tribunal Regional do Trabalho da 5a Região, v. 4, n. 1, 2002. p 41-61;

11 BONAVIDES, Paulo. A quinta geração de direitos fundamentais. Revista Brasileira de Direitos Fundamentais \& Justiça, v. 2, n. 3, 2008. p 82-93; 
Importante salientar que essa divisão em gerações está amparada no surgimento histórico desses direitos, sendo que atualmente busca-se utilizar o termo dimensões ${ }^{12}$ de direitos, evitando assim o viés cronológico e de substituição inerente a ideia do termo geração.

\title{
3.1. O CONCEITO DE DIREITOS HUMANOS X FUNDAMENTAIS
}

No que se refere as diversas concepções sobre os direitos humanos e seus diversos conceitos descreve Fabio Konder Comparato que a doutrina contemporânea os distinguem dos direitos fundamentais mostrando que esses nada mais são que direitos humanos consagrados pelo Estado por meio de normas escritas ${ }^{13}$.

Desta maneira, é possível analisar de forma breve que ocorre uma diferenciação na nomenclatura em relação ao local onde a norma esta positivada. Deste modo, os direitos humanos são normas internacionais que fazem parte do Direito Internacional Público, como a Declaração Universal dos Direitos Humanos e o Pacto de São José da Costa Rica; já os direitos fundamentais estão positivados nas leis internas de cada país a exemplo da Constituição da República Federativa do Brasil.

Sobre os direitos fundamentais da pessoa humana no ordenamento constitucional escreve Delgado

\begin{abstract}
Os direitos fundamentais da pessoa humana dizem respeito àqueles que são inerentes ao universo de sua personalidade e de seu patrimônio moral, ao lado daqueles que são imprescindíveis para garantir um patamar civilizatório mínimo inerente à centralidade da pessoa humana na vida socioeconômica e na ordem jurídica. Trata-se, por exemplo, dos direitos individuais e coletivos elencados no
\end{abstract}

\footnotetext{
12 JÚNIOR, Diógenes; NOGUEIRA, José Eliaci. Gerações ou dimensões dos direitos fundamentais. Âmbito Jurídico, Rio Grande, 2012;

13 COMPARATO, Fabio Konder. A afirmação histórica dos direitos humanos 7 ed rev atual, São Paulo: Saraiva: 2010. pag.239.
} 
Capítulo I ("Dos Direitos e Deveres Individuais e Coletivos") do Título I, a par dos direitos individuais e sociais elencados no Capítulo li ("Dos Direitos Sociais") do mesmo Título $\mathrm{L}^{14}$

Segundo Canotilho essas expressões são frequentemente usadas como sinônimas, porem podemos diferenciá-las devido a sua origem e significado sendo que os direitos do homem são inerentes a todos os povos em todos os tempos, possuindo caráter inviolável intertemporal e universal; ao passo que os direitos fundamentais são direitos do homem jurídico-institucionalizados garantidos e limitados temporalmente vigentes em uma norma jurídica concreta ${ }^{15}$.

0 termo "direitos humanos" tem sido utilizada pela doutrina para identificar os direitos inerentes à pessoa humana na ordem internacional ${ }^{16}$, enquanto que a expressão, direitos fundamentais refere-se a ordenamentos jurídicos específicos, ao reconhecimento de tais direitos frente a um poder político, geralmente reconhecidos por uma constituição.

Sendo assim, as diversas concepções de direitos humanos e direitos fundamentais apontam para uma fundamentação voltada a constante melhora da condição humana, onde todo o sistema internacional de proteção aos direitos humanos e o ordenamento legislativo interno do pais dialogam entre si produzindo um arcabouço jurídico, necessário para o pleno desenvolvimento do sujeito como ente de direito.

14 DELGADO, Mauricio Godinho. DELGADO, Gabriela Neves. A reforma trabalhista no Brasil : com os comentários à Lei n. 13.467/2017. São Paulo: LTr. 2017. pag. 33;

15 CAnotilho, José Joaquim Gomes. Direito Constitucional e Teoria da Constituição. 3 ed. Coimbra: Almedina, 1998. pag.259;

16 SIQUEIRA, Dirceu Pereira; PICCIRILLO, Miguel Belinati. Direitos fundamentais: a evolução histórica dos direitos humanos, um longo caminho. Âmbito Jurídico, Rio Grande, XII, n. 61, p. 06, 2009. 


\section{AS ALTERAÇÕES NA NEGOCIAÇÃO COLETIVA DE TRABALHO PELA LEI 13.467/2017 E OS DIREITOS HU- MANOS FUNDAMENTAIS}

Com a aprovação da lei $n^{\circ} 13.467 / 2017$ ocorreram inúmeras mudanças na legislação trabalhista, no que tange ao direito coletivo do trabalho em especial na análise feita pelos tribunais nos dissídios coletivos.

Neste sentido foram alterados o artigo $8^{\circ}$, sendo inseridos três parágrafos em substituição ao parágrafo único da redação anterior $^{17}$, e o artigo 611-A, com o aumento significativo do rol de direitos que podem ser deliberados nas negociações coletivas, como, por exemplo, a liberdade para pactuar sobre a jornada de trabalho, sobre o intervalo intrajornada, sobre o enquadramento em grau de insalubridade entre outros.

Em relação a essas mudanças afirma Vólia Bomfim Cassar

O caput do art. 611-A da CLT autoriza a ampla flexibilização, aumentando o leque de possibilidades de direitos previstos em lei que podem ser reduzidos ou suprimidos. A norma não teve o objetivo de ampliar direitos, pois isso sempre foi possível. 0 texto afirma que a enumeração desses direitos nos incisos do artigo é meramente exemplificativa. A prevalência do negociado sobre o legislado enfraquece o princípio da indisponibilidade dos direitos legais trabalhistas, assim como derruba o princípio da prevalência da norma mais favorável. Torna os direitos trabalhistas menos públicos e mais privados, transformando a maioria dos direitos contidos na CLT, que não se encontram na Constituição, em direitos disponíveis. ${ }^{18}$

17 BRASIL. Decreto-Lei no 5.452 de $1^{\circ}$ de maio de 1943 (Consolidação das Leis Trabalhistas) - Diário Oficial [da] República Federativa do Brasil. Poder Executivo, Brasília, DF, 09 de Agosto de 1943;

18 CASSAR, Vólia Bomfim. BORGES, Leonardo Dias. Comentários à reforma trabalhista Rio de Janeiro: Forense; São Paulo : Método. 2017.p 76 
Dentro das inúmeras inovações acerca das negociações coletivas e das flexibilizações na norma é importante frisar o caráter exemplificativo do rol dos artigos 611-A, tendo como balizador o artigo 611-B. Sobre isso nos explica Cassar:

\begin{abstract}
Na verdade, o art, 611 -A da CLT aponta alguns dos direitos que podem ser reduzidos ou alterados pela negociação coletiva e o art. 611-B da CLT, a limitação desse poder. Sem dúvida, o art.611-A da CLT permite mais inclusões de outras hipóteses ali não previstas que o art. 611-B da CLT de limitações. A expressão “entre outros” contida no caput do art. 611-A espelha essa intenção do legislador de ampliar ao máximo a flexibilização com finalidade de redução de direitos legais $^{19}$. (grifo nosso)
\end{abstract}

Outrossim, não foram todos os direitos dos trabalhadores que integraram o rol do 611-A, ou seja, que podem ser "flexibilizados" pela convenção ou acordo coletivo, porém, direitos importantes integraram a listagem mencionada como o limite da jornada de trabalho, a redução do intervalo intrajornada, entre outros, utilizando-se das idênticas palavras contidas no caput do referido artigo, e que, com o advento da criação do §3ำ no artigo $8^{\circ}$, segundo Cassar dificultou ao máximo a intervenção do poder judiciário nas negociações coletivas, restringindo as hipóteses de nulidade das normas coletivas ${ }^{20}$.

A lei 13.467/2017 adotou como princípio a intervenção mínima na autonomia da vontade coletiva (princípio que será melhor analisado na sequência), com intuito de dar maior segurança as convenções, acordos e aos seres coletivos, sendo isso refletido tanto no $\S 3^{\circ}$ do art. 8oㅡ. como no art. 611-A da Consolidação das Leis Trabalhistas (CLT).

19 CASSAR, Vólia Bomfim. BORGES, Leonardo Dias. Comentários à reforma trabalhista. Rio de Janeiro: Forense; São Paulo: Método. 2017. p 75;

20 CASSAR, Vólia Bomfim. BORGES, Leonardo Dias. Comentários à reforma trabalhista. Rio de Janeiro: Forense; São Paulo: Método. 2017. p 82 
Sendo assim a perda do caráter público da norma trabalhista, transformando a totalidade dos direitos existentes na Consolidação das Leis Trabalhistas (CLT) em direitos disponíveis acarreta em uma possibilidade iminente de perda ou redução de direitos dos trabalhadores. Isso contraria os princípios como o da proteção ao trabalhador e o princípio da função social no processo trabalhista, este último, na visão de Schiavi, encontra amparo nos princípios constitucionais da função social da propriedade e no da função social do contrato, ${ }^{21}$ sendo assim se há no processo do trabalho um princípio de função social deve-se admitir, consequentemente, o princípio da vedação ao retrocesso social ${ }^{22}$.

0 direito do trabalho advém de uma necessidade humana e possui uma forte ligação com os direitos humanos, nesta relação Delgado afirma que o direito do trabalho é a dimensão social mais significativa dos direitos humanos permitindo a esses um espaço de evolução e cumprindo um papel importante ao garantir um patamar mínimo civilizatório de direitos e garantias no sistema socioeconômico capitalista ${ }^{23}$.

Este patamar mínimo civilizatório está positivado em toda a Constituição Federal ${ }^{24}$, especialmente em seus artigos $5^{\circ}$ e $7^{\circ}$ : como o direito a um salário mínimo, repouso semanal remunerado, férias, licença gestante, condições dignas de trabalho, entre outros.

Com relação as normas de direitos humanos e as mudanças na lei $13.467 / 2017$ afirma Delgado que:

21 Art. 421 do Código Civil: "A liberdade de contratar será exercida em razão e nos limites da função social do contrato";

22 SCHIAVI, Mauro. A reforma trabalhista e o processo do trabalho: aspectos processuais da Lei n. 13.467/17. 1. ed. São Paulo: LTr, 2017. pag 37;

23 Delgado, Mauricio Goldinho. Curso de Direito do Trabalho. 10. ed. São Paulo: LTr, 2011;

24 BRASIL. Constituição da Republica Federativa do Brasil Diário Oficial [da] República Federativa do Brasil. Poder Executivo, Brasília, DF, 05 de Outubro de 1988; 
Esse processo de desarticulação extremada das premissas constitucionais de proteção ao trabalho, promovido pela Lei n. $13.467 / 2017$, também se apresenta como um processo de desarticulação do conjunto normativo de proteção aos direitos trabalhistas firmado na perspectiva do Sistema Internacional de Direitos Humanos, circunstância que possibilita a submissão da referida lei ao eventual juízo de constitucionalidade e também ao eventual juízo de convencionalidade igualmente denominado de controle de convencionalidade. ${ }^{25}$

Sendo assim, as mudanças realizadas no direito coletivo do trabalho, devem ser observadas com cautela. Essas articulações são movidas com o intuito de desamparar o Estado Social e reduzir direitos dos trabalhadores. Sobre a utilização do direito coletivo do trabalho para a redução de direitos nos ensina Delgado:

Insistentemente, a Lei n.13.467/2017 desnatura o sentido constitucional de proteção ao trabalho. É que a Constituição se inspira no conceito de negociação coletiva trabalhista como instrumento de aperfeiçoamento das condições de trabalho (o princípio da norma mais favorável, aliás, é que abre o caput do art. 7o da Constituição Federal, em cujos incisos VI, XIII e XVI se insere a referência à negociação coletiva trabalhista). Não há, na Constituição e nas normas internacionais vigorantes no Brasil, a ideia de negociação coletiva trabalhista como veículo para a precarização de direitos individuais e sociais fundamentais trabalhistas. ${ }^{26}$

25 DELGADO, Mauricio Godinho. DELGADO, Gabriela Neves. A reforma trabalhista no Brasil: com os comentários à Lei n. 13.467/2017. São Paulo: LTr. 2017. p 73;

26 DELGADO, Mauricio Godinho. DELGADO, Gabriela Neves. A reforma trabalhista no Brasil: com os comentários à Lei n. 13.467/2017. São Paulo: LTr. 2017. p 80; 
Deste modo, quaisquer alterações advindas por meios inválidos, que desrespeitem os princípios do direito do trabalho e aos princípios internacionais dos direitos humanos, irão ferir os direitos sociais e, portanto, a dignidade da pessoa humana consagrado no artigo $1^{\circ}$, inciso III, do diploma constitucional pátrio. Sobre a observância desse preceito fundamental para o ordenamento jurídico nos esclarece Cláudia Honório

Já em seu primeiro artigo, consagra a dignidade da pessoa humana como um dos fundamentos da República Federativa (art. 1ํㅜㄴ, inc. III), em evidente opção do perfil do Estado Democrático de Direito pretendido. Em patamar axiológico-normativo superior, a dignidade da pessoa humana constitui-se como valor-fonte do sistema normativo pátrio ${ }^{1}$, irradiando conteúdo para todo o ordenamento jurídico, sendo sua proteção dever dos poderes estatais e de toda a sociedade. ${ }^{27}$

Sendo assim, por ser tratar de um direito fundamental garantido no texto constitucional pátrio, nenhuma norma infraconstitucional poderia reduzir ou suprimir tais direitos já consagrados. Conforme brilhantemente explicou Hans Kelsen, (1998 p. 155) ${ }^{38}$ : a ordem jurídica não é um sistema de normas jurídicas ordenadas no mesmo plano, situadas umas ao lado das outras, mas é uma construção escalonada de diferentes camadas ou níveis de normas jurídicas.

Conquanto, o legislador, ao efetuar as mudanças nos artigos analisados, buscou prestigiar a negociação direta entre as partes envolvidas e limitou a avaliação da justiça especializada quanto ao conteúdo do instrumento normativo coletivo, devendo considerar

27 HONORIO, Claudia. Manual de apoio - inconstitucionalidades da lei 13.467/2017: A proteção ao trabalho na constituição da república federativa do brasil. Ministério Público do Trabalho. 2017; ${ }^{38}$ KELSEN, Hans. Teoria pura do direito [tradução João Baptista Machado]. 6⿳a ed. São Paulo: Martins Fontes, 1998; p,155; 
apenas a legitimidade de parte, o objeto e a forma adotada, nos estritos termos do artigo 104 do Código Civil, como determina a nova lei ${ }^{28}$.

Precisamente, quando o juiz é instado a dirimir um conflito, está obrigado a examinar as questões que lhe são submetidas, como determina o artigo 5ํㅡ, XXXV, da Constituição Federal, que dispõe que "a lei não excluirá da apreciação do Poder Judiciário lesão ou ameaça a direito". Conquanto, ao cumprir com esta determinação constitucional, tem-se que o artigo 489 do Código de Processo Civil considera, em seus elementos essenciais da sentença, o seguinte: a) os fundamentos, em que o juiz analisará a questões de fato e de direito; b) o dispositivo, em que o juiz resolverá as questões principais que as partes lhe submeterem.

Assim, nesta linha de pensamento, não poderá o julgador se exonerar do exame do mérito de um pedido que, por exemplo, busque a declaração de nulidade de certa cláusula de acordo ou de convenção coletiva de trabalho ${ }^{29}$. Consequentemente, não poderá o juízo não analisar, mesmo que em um dissídio individual, um pedido que invoque lesão ou ameaça a direito por meio de uma negociação coletiva.

É notório que essas alterações já provocam tentativas de retrocesso pelas partes do direito coletivo do trabalho (sindicato dos empregadores ou empresas versus sindicato dos trabalhadores) por meio de distorções no entendimento da nova norma, a título exemplificativo seguem jurisprudências encontradas no Egrégio Tribunal Regional do Trabalho da $4^{\circ}$ região:

AÇÃO ANULATÓRIA DE CLÁUSULAS CONVENCIO-

28 MANUS, Pedro Paulo Teixeira. Limites à análise da negociação coletiva conforme a reforma trabalhista. Disponível em: <https://www.conjur. com.br/2017-out-06/reflexoes-trabalhistas-limitesanalise-negociacaocoletiva-conforme-reforma-trabalhista>. Acessado em 10/10/2018.

29 MANUS, Pedro Paulo Teixeira. Limites à análise da negociação coletiva conforme a reforma trabalhista. Disponível em: <https://www.conjur. com.br/2017-out-06/reflexoes-trabalhistas-limitesanalise-negociacaocoletiva-conforme-reforma-trabalhista>. Acessado em 10/10/2018. 
NAIS. JOVEM APRENDIZ. Nula a cláusula de Convenção Coletiva de Trabalho que afronta o art. 429 da CLT, ao autorizar as empresas do segmento de asseio e conservação a contratarem a quantidade de jovens aprendizes prevista em lei com base exclusivamente no número de trabalhadores lotados em suas atividades administrativas e preencherem seu quadro de pessoal com $5 \%$, no mínimo, de trabalhadores com menos de 25 anos de idade. (TRT da 4⿳a Região, Seção de Dissídios Coletivos, 002065190.2018.5.04.0000 AACC, em 04/10/2018, Desembargador Joao Pedro Silvestrin) (grifo nosso)

O ilustre desembargador João Pedro Silvestrini, relator da presente ação, alude em seu voto o fato que, com relação ao jovem aprendiz, constava no projeto original o item XII do artigo 611A com previsão de que a convenção coletiva e o acordo coletivo de trabalho teria prevalência sobre a Lei quando, entre outros, dispusesse sobre identificação e cargos que demandem a fixação da cota de aprendiz. Contudo, referido item (XII do art. 611-A, no Projeto) foi excluído, justamente por estar em conflito com o disposto no inciso XXIV do art. 611-B.

Sendo assim, através de tal explicação percebe-se que o projeto de lei visava uma maior flexibilização, como no exemplo em epigrafe, que permitia a supressão/redução das medidas de proteção ao trabalho legal de crianças e adolescentes.

Já na Ação Anulatória de Cláusula Convencional sob no 002199628.2017.5.04.0000, o sindicato patronal utilizou as novas regras da reforma para tentar validar pratica que fere diretamente o disposto no art. 7ํ, XIII, da Constituição Federal, sendo assim, direito fundamental do trabalhador:

EMENTA AÇÃO ANULATÓRIA DE CLÁUSULA CONVENCIONAL. PRORROGAÇÃO DE JORNADA. ESCALA $4 X 2$. É nula a norma coletiva que autoriza a pror- 
rogação da jornada até 11 horas diárias em escala de $4 \times 2$ (quatro dias de trabalho por dois dias de descanso), face evidente afronta aos artigos 59 caput da CLT e 7ํㅜ, XIII, da Constituição Federal, na medida em que implica extrapolação habitual da jornada diária e semanal sem respectiva compensação. (TRT da 4⿳a Região, Seção de Dissídios Coletivos, 0021996-28.2017.5.04.0000 AACC, em 06/06/2018, Desembargador Claudio Antônio Cassou Barbosa)

No presente voto o ilustre desembargador Claudio Antônio Cassou Barbosa, relator da presente ação, explica que a reforma vem desassociada dos avanços e conquistas históricas dos trabalhadores, deste modo, demonstra desconexão do legislador com a realidade das relações trabalhistas.

Ainda, importante ressaltar a ilustre explicação trazida pelo desembargador sobre a norma trabalhista:

Ainda que assim não fosse, não se pode olvidar que, a par do prestígio conferido à autonomia coletiva da vontade pela Lei $13.467 / 2017$, esta não é absoluta. Veja-se, por exemplo, que o próprio artigo 611-B da CLT, também introduzido pela lei em questão traz hipóteses de objetos ilícitos de Convenção Coletiva. Outrossim, é certo que, mesmo após a inovação legislativa em comento, a autonomia coletiva da vontade continua encontrando limitações no texto Constitucional.

Veja-se que, embora a Constituição Federal no inciso XXVI, do artigo 7ำ disponha sobre o reconhecimento das convenções e acordos coletivos de trabalho como direito do trabalhador, prevê de forma taxativa, nos incisos VI, XIII e XIV os direitos com relação aos quais é possível a flexibilização mediante norma coletiva, quais sejam: a irredutibilidade do salário, a compensação de horários e redução da jornada, bem assim a jornada de seis 
horas para o trabalho realizado em turnos ininterruptos de revezamento.

A norma coletiva, no aspecto, implica renúncia a direito indisponível, frente à autonomia privada coletiva, e desconsidera o disposto em norma de ordem pública, de natureza imperativa, que visa assegurar a higiene, saúde e segurança do trabalho e, portanto, viola a garantia prevista no art. 7으, inc. XXII, da CF e o direito fundamental à saúde expresso no art. 6ํㅡ c/c 196 da CF.

Ao analisar os julgados supracitados fica evidente que, posterior a entrada em vigor da reforma trabalhista, há a intenção de suprimir direitos já garantidos os trabalhadores a quase um século no Brasil. 0 que, frente aos avanços dos direitos humanos em escala mundial, é uma afronta direta a dignidade da pessoa humana, princípio norteador do ordenamento jurídico brasileiro.

Com relação a flexibilização dos direitos e a o texto constitucional, João Batista Berthier Leite Soares traz o conceito de flexibilização em condicionada ou incondicionada: na primeira, a redução ou supressão de direitos é acompanhada de uma contrapartida consistente; na segunda, o trabalhador sofre com uma redução ou supressão sem receber nenhuma contrapartida ${ }^{30}$.

A flexibilização incondicionada encontra-se vedada pelo caput do artigo $7^{\circ}$, sendo assim Soares defende que o inciso XXVI, do próprio artigo $7^{\circ}$ deve passar pelo filtro proposto pelo caput do referido artigo. Isto é, pode ser admitida em certa medida a flexibilização condicionada, mas, em princípio, não se pode permitir a flexibilização incondicionada.

Um dos elementos utilizados para justificar que a negociação coletiva realizada por entidades representativas dos trabalhadores e empregadores possa prevalecer sobre as normas da CLT assim,

30 SOARES, João Batista Berthier Leite. Manual de apoio - inconstitucionalidades da lei 13.467/2017: a reforma trabalhista, as negociações coletivas e a constituição da república. Ministério Público do Trabalho. 2017; 
acarretando possíveis flexibilizações e supressões de direitos foi o chamado princípio da autonomia coletiva da vontade.

Sobre a observação desse preceito versus a função do direito coletivo do trabalho explica Jorge Souto Maior afirma que o espaço de negociação coletiva é preservado para agir como uma forma de ampliação de direitos para a criação de normas jurídicas voltadas à complementação e melhoria dos direitos individuais. Deste modo não há espaço para retrocessos e perda de direitos em negociação coletiva. Ela foi criada para complementar os avanços nos direitos individuais do trabalho ${ }^{31}$.

\section{AS LIMITAÇÕES IMPOSTAS AOS TRIBUNAIS PELA LEI No13.467/2017}

As mudanças realizadas no ordenamento jurídico trabalhista trouxeram limitações ao papel dos tribunais na análise do mérito nos acordos e nas convenções coletivas. As alterações ocorridas no artigo $8^{\circ}$, com a inserção dos parágrafos um, dois e três atuam como um entrave ao trabalho da justiça, in verbis:

Art. $8^{\circ}$ - As autoridades administrativas e a Jus-
tiça do Trabalho, na falta de disposições legais
ou contratuais, decidirão, conforme o caso, pela
jurisprudência, por analogia, por equidade e outros
princípios e normas gerais de direito, principal-
mente do direito do trabalho, e, ainda, de acordo
com os usos e costumes, o direito comparado, mas
sempre de maneira que nenhum interesse de classe
ou particular prevaleça sobre o interesse público
$\S 1$ o 0 direito comum será fonte subsidiária do
direito do trabalho.
$\S \quad 2^{\circ}$ Súmulas e outros enunciados de
jurisprudência editados pelo Tribunal Superior do

31 MAIOR, Jorge Luiz Souto. A "reforma” trabalhista e seus reflexos no Direito Coletivo do Trabalho. Disponivel em < https://www.jorgesoutomaior.com/blog/a-reforma-trabalhista-e-seusreflexos-no-direito-coletivodo-trabalho>. Acessado em 15/09/2018. 
Trabalho e pelos Tribunais Regionais do Trabalho não poderão restringir direitos legalmente previstos nem criar obrigações que não estejam previstas em lei

$\S 3^{\circ}$ No exame de convenção coletiva ou acordo coletivo de trabalho, a Justiça do Trabalho analisará exclusivamente a conformidade dos elementos essenciais do negócio jurídico, respeitado o disposto no art. 104 da Lei ${ }^{\circ}$ 10.406, de 10 de janeiro de 2002 (Código Civil), e balizará sua atuação pelo princípio da intervenção mínima na autonomia da vontade coletiva ${ }^{32}$.

Segundo Mauro Schiavi o referido parágrafo deve ser considerado inconstitucional, uma vez que contraria o livre acesso a justiça, previsto no artigo $5^{\circ}$,

XXX da CFRB e viola os incisos VI, XIII e XIV, também do ordenamento constitucional, que, além dos requisitos formais do negócio jurídico, exigem que para a flexibilização de direitos, exista efetiva negociação coletiva e observâncias dos direitos mínimos trabalhistas, previstos no ordenamento jurídico pátrio. Além disso, o referido parágrafo é restritivo a incidência de normas constitucionais relativas a proteção do trabalho humano ${ }^{33}$.

Afirma Delgado que os parágrafos $2^{\circ}$ e $3^{\circ}$ do artigo $8^{\circ}$ da referida norma trabalhista desrespeitam o princípio constitucional da separação de poderes e da independência do poder judiciário, visando criar um sistema de cidadania de segunda classe na sociedade civil e política brasileira, criando uma chamada cidadania trabalhista $^{34}$.

32 BRASIL. Decreto-Lei no 5.452 de $1^{\circ}$ de maio de 1943 (Consolidação das Leis Trabalhistas) - Diário Oficial [da] República Federativa do Brasil. Poder Executivo, Brasília, DF, 09 de Agosto de 1943;

33 SCHIAVI, Mauro. A reforma trabalhista e o processo do trabalho : aspectos processuais da Lei n. 13.467/17. 1. ed. São Paulo : LTr, 2017. p 37.

34 DELGADO, Mauricio Godinho. DELGADO, Gabriela Neves. A reforma trabalhista no Brasil : com os comentários à Lei n. 13.467/2017. São Paulo: LTr. 2017. p 80, 
Assim, para essas pessoas, o poder judiciário não pode avaliar os prováveis desrespeitos a Constituição e as normas internacionais de direitos humanos vigentes no Brasil, uma vez que deve aceitar quaisquer eventuais retrocessos celebrados pela negociação coletiva do trabalho. o patamar mínimo civilizatório não será aplicado a essas pessoas, afastando o poder judiciário na atuação para corrigir lesões gravíssimas de direitos.

Inúmeras associações e organizações da sociedade civil e também do Estado se insurgiram contra essas limitações e alterações entre elas a Associação Nacional da Magistratura do Trabalho (ANAMATRA) que em sua $2^{\circ}$ jornada de Direito Material e Processual do Trabalho, realizada em Brasília nos dias 09 e 10 de outubro de 2017, foram aprovados 125 enunciados em relação ao texto da reforma, entre eles o enunciado $\mathrm{n}^{\circ} 2$, in verbis:

INTERPRETAÇÃO E APLICAÇÃO DA LEI $13.467 / 2017$

OS JUÍZES DO TRABALHO, À MANEIRA DE TODOS OS DEMAIS MAGISTRADOS, EM TODOS OS RAMOS DO JUDICIÁRIO, DEVEM CUMPRIR E FAZER CUMPRIR A CONSTITUIÇÃO E AS LEIS, O QUE IMPORTA NO EXERCÍCIO DO CONTROLE DIFUSO DE CONSTITUCIONALIDADE E NO CONTROLE DE CONVENCIONALIDADE DAS LEIS, BEM COMO NO USO DE TODOS OS MÉTODOS DE INTERPRETAÇÃO/APLICAÇÃO DISPONÍVEIS. NESSA MEDIDA: I. REPUTA-SE AUTORITÁRIA E ANTIRREPUBLICANA TODA AÇÃO POLÍTICA, MIDIÁTICA, ADMINISTRATIVA OU CORREICIONAL QUE PRETENDER IMPUTAR AO JUIZ DO TRABALHO O "DEVER" DE INTERPRETAR A LEI 13.467/2017 DE MODO EXCLUSIVAMENTE LITERAL/GRAMATICAL; II. A INTERPRETAÇÃO JUDICIAL É ATIVIDADE QUE TEM POR ESCOPO O DESVELAMENTO DO SENTIDO E DO ALCANCE DA LEI TRABALHISTA. É FUNÇÃO PRIMORDIAL DO PODER JUDICIÁRIO TRABALHISTA JULGAR AS RELAÇÕES DE TRABALHO E DIZER O DIREITO NO CASO CONCRETO, OBSERVANDO O 
OBJETIVO DA REPÚBLICA FEDERATIVA DO BRASIL DE CONSTRUIR UMA SOCIEDADE MAIS JUSTA E IGUALITÁRIA. EXEGESE DOS ARTIGOS 1으. 2ํㅜㄴ $3^{\circ}$, 5ㅇ, INCISO XXXV, 60 E 93, IX E 114 DA CRFB; III.

INCONSTITUCIONALIDADE DO § 2 E DO § $3^{\circ}$ DO ARTIGO 8 DA CLT E DO ARTIGO 611-A, §1ํㅡ, DA CLT. SERÁ INCONSTITUCIONAL QUALQUER NORMA QUE COLIME RESTRINGIR A FUNÇÃO JUDICIAL DE INTERPRETAÇÃO DA LEI OU IMUNIZAR O CONTEÚDO DOS ACORDOS E CONVENÇÕES COLETIVAS DE TRABALHO DA APRECIAÇÃO DA JUSTIÇA DO TRABALHO, INCLUSIVE QUANTO À SUA CONSTITUCIONALIDADE, CONVENCIONALIDADE, LEGALIDADE E CONFORMIDADE COM A ORDEM PÚBLICA SOCIAL. NÃO SE ADMITE QUALQUER INTERPRETAÇÃO QUE POSSA ELIDIR A GARANTIA DA INAFASTABILIDADE DA JURISDIÇÃO, ADEMAIS, POR OFENSA AO DISPOSTO NO ART. 114, I, DA CF/88 E POR INCOMPATIBILIDADE COM OS PRINCÍPIOS DA SEPARAÇÃO DOS PODERES, DO ACESSO A JUSTIÇA E DA INDEPENDÊNCIA FUNCIONAL ${ }^{35}$.

Como se não bastasse a literalidade do enunciado $\mathrm{n}^{\circ} 2 \mathrm{com}$ relação a flagrante inconstitucionalidade das mudanças do artigo $8^{\circ}$, o enunciado $n^{\circ} 25$, em relação aos limites entre o negociado com o legislado declara:

NEGOCIADO SOBRE LEGISLADO: LIMITES

NOS TERMOS DO ART. 5요 § 2º, DA CONSTITUIÇÃO FEDERAL, AS CONVENÇÕES E ACORDOS COLETIVOS DE TRABALHO NÃO PODEM SUPRIMIR OU REDUZIR DIREITOS, QUANDO SE SOBREPUSEREM OU CONFLITAREM COM AS CONVENÇÕES INTERNACIONAIS DO TRABALHO E OUTRAS NORMAS DE HIERARQUIA CONSTITUCIONAL OU SUPRALEGAL

35 ANAMATRA (Brasília). Enunciados aprovados na $2^{\mathbf{a}}$ jornada. Disponível em: <http://www.jornadanacional.com.br/listagem-enunciados-aprovadosvis1.asp>. Acessado em 10/10/2018. 
RELATIVAS À PROTEÇÃO DA DIGNIDADE HUMANA E DOS VALORES SOCIAIS DO TRABALHO E DA LIVRE INICIATIVA.

Veja que o enunciado é claro com relação aos limites da negociação coletiva, devendo a mesma, assim como todas as demais normas, respeitar os ditames constitucionais, sendo assim não podendo contrariar seus princípios, como o da vedação ao retrocesso social e o princípio fundamental da republica que é o da garantia da dignidade da pessoa humana.

O Ministério Público do Trabalho (MPT), com o advento da mudança legislativa edita uma recomendação aos sindicatos de trabalhadores da alimentação onde entre outras situações adverte:

$[\ldots]$

CONSIDERANDO que nos últimos anos em razão de importantes esforços do Ministério Público do Trabalho, do Ministério do Trabalho, dos sindicatos e das empresas, verifica-se uma melhoria nas condições de trabalho, avanço que pode ser revertido em face da aprovação da lei 13.467/17 (lei da Reforma Trabalhista).

[...]

CONSIDERANDO que as recentes alterações trazidas pela lei 13.467/2017 (Reforma Trabalhista), devem ser sempre interpretadas sob a ótica dos princípios constitucionais assecuratórios dos direitos fundamentais dos trabalhadores, relacionados ao trabalho decente (art. $7^{\circ}$ ), à dignidade da pessoa humana (art. $1^{\circ}, \mathrm{III}$ ), aos valores sociais do trabalho (art. $1^{\circ}, \mathrm{IV}$ ), à proteção à saúde (art. $6^{\circ}$ e 196), à construção de uma sociedade justa livre e solidária (art. $3^{\circ}$, I) à promoção do bem de todos (art . $3^{\circ}, \mathrm{IV}$ ), à ordem econômica fundada na valorização do trabalho humano e na livre iniciativa que tem por fim assegurar a todos existência digna, conforme os ditames da justiça social (art. 170 da CF).

[...] 
CONSIDERANDO os exatos termos do Preâmbulo da Declaração da

Filadélfia (1944), da Constituição da Organização Internacional do Trabalho, dispõem que “(...) existem condições de trabalho que implicam, para grande número de indivíduos, miséria e privações, e que o descontentamento que daí decorre põe em perigo a paz e a harmonia universais, e considerando que é urgente melhorar essas condições no que se refere, por exemplo, à regulamentação das horas de trabalho, à fixação de uma duração máxima do dia e da semana de trabalho, ao recrutamento da mão-de-obra, à luta contra o desemprego, à garantia de um salário que assegure condições de existência convenientes, à proteção dos trabalhadores contra as moléstias graves ou profissionais e os acidentes do trabalho" $(. . .)^{36}$

Um grande exemplo de flexibilização é a alteração do parágrafo $3^{\circ}$ do já mencionado artigo $8^{\circ}$, que se baseia nas atuações dos tribunais em um preceito de intervenção mínima na autonomia da vontade coletiva, fazendo com que o judiciário atue de forma a garantir uma intervenção mínima, que, segundo Jorge Souto Maior, cria, ainda que sem base material alguma, o tal "princípio da intervenção mínima na autonomia da vontade coletiva"37.

Outro documento importante do MPT é a nota técnica número 8, lançada em 26 de junho de 2017, quando o projeto de lei ainda tramitava pelo Senado, onde o referido órgão aponta as inúmeras inconstitucionalidades, entre elas a do artigo 611A:

36 MINISTÉRIO PÚBLICO DO TRABALHO (Florianópolis). Recomendação referente ao procedimento promocional 569/2011. Disponível em:

<tp://www.prt12.mpt.mp.br/images/Ascom/PRT12/2017/Documentos_PDF/ rec1-final.pdf>. Acessado em 09/10/2018;

37 MAIOR, Jorge Luiz Souto. A "reforma" trabalhista e seus reflexos no Direito Coletivo do Trabalho. Disponível em < https://www.jorgesoutomaior.com/blog/a-reforma-trabalhista-e-seusreflexos-no-direito-coletivodo-trabalho>. Acessado em 15/09/2018. 
Mecanismo também utilizado pelo PLC 38/2017 para desregulamentar o trabalho encontra-se no art. 611-a, que consiste na imposição de prevalência das normas negociais sobre as normas constitucionais e legais de proteção ao trabalho - o negociado sobre o legislado- em toda e qualquer situação, inclusive para extinguir ou reduzir direitos sem uma correspondente compensação, ã exceção apenas do previsto no 611-B [...]

A norma viola a finalidade constitucional da negociação coletiva, prevista como direito fundamental do trabalhador, no art. 7/,xxvi da Constituição, que consiste em garantir que, por meio desse instrumento, os trabalhadores coletivamente organizados em sindicatos possam conquistar “ outros (direitos) que visem à melhoria de sua condição social" ${ }^{38} \cdot{ }^{39}$

Até esse momento o que se verificou foi justamente um ataque sistemático aos direitos e garantias dos trabalhadores visto que como já demonstrado, as negociações coletivas realizadas após a aprovação da reforma criaram situações desfavoráveis, contrariando assim o texto constitucional e os direitos humanos como um todo.

Corroborando com todos estes enunciados encontramos maior respaldo do tema é imperioso afirmar o rompimento aos princípios constitucionais e as motivações que levam a alteração da lei, sobre isso explana Vitor Hugo Valente:

É de se destacar que essa motivação inicial rompe com a própria razão de ser da Justiça Laboral,

38 MINISTÉRIO PÚBLICO DO TRABALHO (Brasília). nota técnica nº8 de 26 de junho de 2017 da secretaria de relações institucionais do Ministério Publico do Trabalho (MPT) Disponível em:

<http://portal.mpt.mp.br/wps/wcm/connect/portal_mpt/ce4b9848-f7e4-

39 d816b3c6470e4 ad/Nota+t\%C3\%A9cnica+n\%C2\%BA+8.2017.pdf?MOD=AJPERES\&CVID=lPC HY69 >. Acessado em 10/10/2018 
visto que questiona sua atuação enquanto fiscal máximo de negociações coletivas, as quais podem, por óbvio, impor condições degradantes de trabalho e, por essa causa, venham a ser questionadas judicialmente ${ }^{40}$.

Outrossim, sobre o conceito contemporâneo de autonomia da vontade coletiva é correto afirmar que ela decorre de uma vontade comum de um grupo, não podendo ser confundida com a vontade individual dos membros que a compõem, tratando-se de interesse coletivo por englobar bens jurídicos pertencentes a toda a coletividade, empenhando-se para satisfazer as necessidades comuns de todos que a compõem abrangido seu status de poder regulatório a partir do interesse coletivo de um grupo, detentor e executor desse poder ${ }^{51}$.

A luz da observação pelo prisma constitucional, as alterações realizadas não devem ser validas, uma vez que ferem o princípio da vedação ao retrocesso social princípio este brilhantemente explicado por Canotilho.

(...) os direitos sociais e econômicos (ex.: direito dos trabalhadores, direito à assistência, direito à educação), uma vez obtido um determinado grau de realização, passam a constituir, simultaneamente, uma garantia institucional e um direito subjectivo. A "proibição de retrocesso social" nada pode fazer contra as recessões e crises econômicas (reversibilidade fáctica), mas o princípio em análise limita a reversibilidade dos direitos adquiridos (ex.: segurança social, subsídio de desemprego,

40 FOGAÇA, Vitor Hugo Bueno; VALENTE, Nara Luiza. A reforma trabalhista brasileira e a proibição constitucional de retrocesso social: uma análise preliminar à luz da principiologia laboral. Revista Eletrônica TRT9 - Ed. Especial Reforma Trabalhista IV, $n$ o 67. Ano VII, 2018; ${ }^{51}$ LOPES, Keline Bronner et al. A (in) compatibilidade da autonomia privada coletiva irrestrita com o sistema sindical brasileiro: a negociação coletiva no PL 6.787/16. 2017; 
prestações de saúde), em clara violação do princípio da protecção da confiança e da segurança dos cidadãos no âmbito econômico, social e cultural, e do núcleo essencial da existência mínima inerente ao respeito pela dignidade da pessoa humana ${ }^{41}$.

Tal vedação, consagrada pelo artigo $7^{\circ}$ da constituição federal, deve ser aplicada a todas as relações de trabalho e, principalmente, no ordenamento infraconstitucional do trabalho, sendo assim o texto da referida reforma busca mitigar ou reduzir direitos sociais, prejudicando o empregado hipossuficiente nas relações de trabalho. Pelo que pode ser extraído do texto constitucional o correto é manter um modelo que possibilite uma maior proteção ao trabalhador

As alterações realizadas no artigo $8^{\circ}$ ferem a própria autonomia do direito do trabalho em si. Schiavi ensina que o direito do trabalho é uma ciência autônoma, com objeto próprio diverso do direito civil, sendo que este deve ser utilizado apenas de maneira subsidiaria, no caso concreto, em caso de omissão na legislação específica ${ }^{42}$.

Sendo assim a utilização da normatização cível como regra, como previsto no parágrafo terceiro do referido artigo, aparece como uma afronta a própria independência das relações de trabalho como objeto de estudo cientifico em área especializada.

A necessidade de uma participação mais efetiva dos órgãos da justiça do trabalho na análise das negociações coletivas se impera nos princípios da proteção, da manutenção da condição mais benéfica e do in dubio pro operarium. Mas, sem dúvida o principal princípio utilizado é o princípio da indisponibilidade dos direitos trabalhistas. Para Delgado o princípio citado talvez

41 CANOTILHO, José Joaquim Gomes. Direito constitucional e teoria da constituição. 7. ed. 9. reimp. Coimbra: Almedina, 2003. Pag. 338-339;

42 SCHIAVI, Mauro. A reforma trabalhista e o processo do trabalho: aspectos processuais da Lei n. 13.467/17 1. ed. São Paulo : LTr, 2017. p 55. 
seja o maior instrumentalizador na tentativa de equalizar as relações entre patrões e empregados ${ }^{43}$.

\section{CONCLUSÃO}

Desde o início, o Direito do Trabalho, como ramo especifico da ciência jurídica enfrenta resistência para sua implantação. Quando da apresentação do anteprojeto de lei que instituiu essa especialidade, em 1935 inúmeros intelectuais eram contra a sua implantação, argumentando que os conflitos trabalhistas não necessitavam de novos órgãos, pois bastava seguir o ordenamento contratual civil, acusando-a de ser apenas uma organização fascista de dominação do Estado nas relações do trabalho ${ }^{44}$.

A história já nos mostrou que as violações feitas a qualquer direito básico e inerente a pessoa humana são tidos como grave ameaça e repelidos pela sociedade como um todo. 0 presente momento histórico é de restrição aos avanços conquistados pela classe trabalhadora e pela sociedade como um todo, o recente e desenfreado avanço do capital em relações ao interesse público é protagonista nesse processo.

Restou demonstrado no presente trabalho que os direitos trabalhistas são considerados direitos humanos fundamentais e, portanto, qualquer mudança que vir a ser feita, deve ser realizada com cautela.

Quedou caracterizado que a Lei 13.467/2017 veio como uma avalanche crescente, com fito de regularizar uma sociedade em crise política e franca desaceleração econômica, mas que, todavia, não logrou o êxito esperado, pois em decorrente da pressa e má observação dos princípios e fundamentos básicos desta justiça especializada, acabou por trazer mais dúvidas e insegurança do que calma aos anseios prévios.

43 DELGADO, Mauricio Godinho. Curso de Direito do Trabalho. $8^{\circ}$ ed. São Paulo Ltr, 2006. p 186.

44 FRANCO, Raquel Veras. A Justiça do Trabalho entre dois extremos - Reflexões sobre sua 
As normas, ao serem revisadas, não devem servir como objeto de supressão de diretos e garantias dos trabalhadores, pois devem observar, como toda norma jurídica, os princípios consagrados, primeiramente, pela Constituição Federal, em um segundo plano, devem respeitar os acordos e pactos internacionais que o Brasil tenha ratificado e faça parte no âmbito do direito internacional, principalmente aos que estão relacionados com os direitos humanos; já, em um terceiro momento, deverão respeitar as especificidades da sociedade brasileira, que comparada com o cenário internacional, ainda esta longe de poder manter a equidade nas relações de trabalho.

Logo, o que foi determinado com a aprovação da lei 13.467/2017 não foi uma modernização da norma trabalhista, vista muito vezes como ultrapassada e incapaz de responder aos complexos problemas da sociedade atual, mas sim o ápice de um desmonte do Estado Social.

Analisados os conceitos trazidos, observa-se que as novas regras imputadas pela reforma, no que tange aos direitos coletivos, buscam tão somente reduzir direitos e, sobretudo, para impedir o que é básico no plano da atuação coletiva, que é o estabelecimento de uma correlação de forças igualitária entre o empregado e o empregador. ${ }^{45}$

No que tange a constitucionalidade da norma, percebe-se que é inconstitucional de forma geral, pois acaba por proporcionar desigualdade e insegurança ao trabalhador, que vê seus direitos aquém das entidades sindicais, que, para sua manutenção, irão negociar de forma "parcial" para o empregador.

Não obstante, o caráter liberal da norma posta, com o intuito de supor que o trabalhador possa negociar em pé de igualdade

45 MAIOR, Jorge Luiz Souto. A "reforma" trabalhista e seus reflexos no Direito Coletivo do Trabalho. Disponível em <https://www.jorgesoutomaior.com/blog/a-reforma-trabalhista-e-seusreflexos-no-direito-coletivodo-trabalho >. Acessado em 15/09/2018. 
com o empregador, demonstra uma intenção nefasta do legislador, pois nunca o detentor do meios de produção será igual aquele que possui apenas sua força de trabalho para sobreviver. As forças sempre estão desproporcionais, onde o lado mais frágil, o do trabalhador e de seu sindicato sempre sairão perdendo.

A Justiça do Trabalho possui função determinante para evitar a derrocada dos direitos dos trabalhadores, retirar dela seu caráter de ação de proteger o trabalhador contraria princípios como o da proteção e o do benefício da norma mais benéfica. Estão amordaçando a Justiça do Trabalho, tirando-lhe sua autonomia e promovendo o seu esvaziamento em troca de uma relação de trabalho precarizada, valendo-se assim nas mudanças realizadas na CLT.

Até o presente momento é possível concluir que em decorrência ao todo explanado durante o trabalho, a possibilidade de ameaça aos direitos humanos é real e factível, desta forma, é plenamente aceitável que os fatos decorrentes da reforma trabalhista possam ser objetos de controle por parte dos órgãos de dessa dos direitos humanos. Outrossim o papel do judiciário é fundamental para evitar a supressão de direitos dos trabalhadores como guardião de direitos e última trincheira na luta pela paz e o bem estar social de todos.

\section{REFERÊNCIAS BIBLIOGRÁFICAS}

BRASIL. Constituição da República Federativa do Brasil Diário Oficial [da] República Federativa do Brasil. Poder Executivo, Brasília, DF, 05 de Outubro de 1988.

BRASIL. Decreto-Lei no 5.452 de 1 de maio de 1943 (Consolidação das Leis Trabalhistas) - Diário Oficial [da] República Federativa do Brasil. Poder Executivo, Brasília, DF, 09 de Agosto de 1943.

BRASIL. Lei ${ }^{\circ} \mathbf{1 3 . 4 6 7}$ de 13 de julho de 2017, que altera o Decreto -Lei 5.452/1943 - Diário Oficial [da] República Federativa do Brasil. Poder Executivo, Brasília, DF, 13 de julho de 2017.

COMPARATO, Fabio Konder. A afirmação histórica dos direitos humanos 7 ed rev atual, São Paulo: Saraiva,2010. 
DELGADO, Mauricio Goldinho. Curso de direito do trabalho. 10 ed São Paulo: LTr, 2011.

MENDES, Gilmar; BRANCO, Paulo Gustavo Gonet. Curso de Direito Constitucional. 6 ed rev. atual. São Paulo, Saraiva, 2011.

CASSAR, Volia Bomfim. Direito do Trabalho. 14 ed. rev. atual. e ampliada - 2 reimpre. Rio de Janeiro. Forense, São Paulo: MÉTODO. 2017.

CASSAR, Vólia Bomfim. BORGES, Leonardo Dias. Comentários à reforma trabalhista Rio de Janeiro: Forense; São Paulo : Método. 2017.

ALMEIDA. Almiro Eduardo de. Emprega-dor: a participação da classe dominante na construção do Direito do trabalho no Brasil - uma história forjada com alienação, estranhamento e ideologia. Rio de Janeiro. Lumen Juris. 2018.

SALET, Ingo Wolfgang. A eficácia dos direitos fundamentais - uma teoria geral dos direitos fundamentais na perspectiva constitucional 11 ed rev. atual. Porto Alegre: Livraria do advogado, 2012.

ONU. Declaração universal dos direitos humanos disponível em HTTPS://www.onu.org.br/img/2014/09/dudh.pdf acesso em 01/06/2018.

BOBBIO. Norberto A era dos direitos; tradução de Carlos Nelson Coutinho - nova Ed. Rio de Janeiro: elsevier, 2004 - 10 reimpressão p. 206.

RODRIGUEZ. Americo Plá. Princípios de Direito do Trabalho, 3aㅡ Ed. São Paulo: Ltr, 2015.

KELSEN, Hans. Teoria pura do direito [tradução João Baptista Machado]. 6a ed. - São Paulo: Martins Fontes, 1998.

DELGADO, Mauricio Goldinho. Direito Coletivo do trabalho. 5 ed. São Paulo: LTr, 2014.

JÚNIOR, DIÓGENES; NOGUEIRA, José Eliaci. Gerações ou dimensões dos direitos fundamentais. Âmbito Jurídico, Rio Grande, a, v. 15, 2012.

LEITE, Carlos Henrique Bezerra. Direito Processual Coletivo do Trabalho - na Perspectiva dos Direitos Humanos. São Paulo: LTr, 2015.

DELGADO, Mauricio Godinho. DELGADO, Gabriela Neves. A reforma trabalhista no Brasil : com os comentários à Lei n. 13.467/2017 São Paulo : LTr, 2017. 
ZAVASCKI, Teori Albino. Direitos fundamentais de terceira geração. Revista da Faculdade de Direito, v. 15, n. 15, 1998.

ALVES, Eliana Calmon. Direitos de quarta geração: biodiversidade e biopirataria. Revista do Tribunal Regional do Trabalho da 5a Região, v. 4, n. 1, p. 41-61, 2002.

BONAVIDES, P. A quinta geração de direitos fundamentais. Revista Brasileira de Direitos Fundamentais \& Justiça, v. 2, n. 3, p. 82-93, 30 jun. 2008

CANOTILHO, José Joaquim Gomes. Direito constitucional e teoria da constituição. 7. ed. 9. reimp. Coimbra: Almedina, 2003.

FRANCO, Raquel Veras. A JUSTIÇA DO TRABALHO ENTRE DOIS EXTREMOS - Reflexões sobre sua instalação. Disponivel em <www. tst.jus.br/historia-da-justicado-trabalho>,. Acessado em 07/11/2018.

SCHIAVI, Mauro. A reforma trabalhista e o processo do trabalho: aspectos processuais da Lei n. 13.467/17 1. ed. São Paulo : LTr, 2017. HONORIO, Claudia. MANUAL DE APOIO - INCONSTITUCIONALIDADES DA LEI 13.467/2017: A PROTEÇÃO AO TRABALHO NA CONSTITUIÇÃO DA REPÚBLICA FEDERATIVA DO BRASIL. Ministério Público do Trabalho. 2017.

MANUS, Pedro Paulo Teixeira. Limites à análise da negociação coletiva conforme a reforma trabalhista. Disponível em: <https://www.conjur. com.br/2017 out-06/reflexoes-trabalhistas-limites-analise-negociacao-coletiva-conforme-reformatrabalhista >. Acessado em 10/10/2018.

MAIOR, Jorge Luiz Souto. A "reforma" trabalhista e seus reflexos no Direito Coletivo do Trabalho. Disponivel em <https://www.jorgesoutomaior.com/blog/a-reformatrabalhista-e-seus-reflexos-no-direitocoletivo-do-trabalho>. Acessado em 15/09/2018.

ANAMATRA (Brasilia). Enunciados aprovados na $2^{\mathbf{a}}$ jornada. Disponível em:

<http://www.jornadanacional.com.br/listagem-enunciados-aprovados-vis1.asp>. Acessado em 10/10/2018.

MINISTÉRIO PÚBLICO DO TRABALHO (Florianópolis). Recomendação referente ao procedimento promocional 569/2011. Dísponivel em: <www.prt12.mpt.mp.br/images/Ascom/PRT12/2017/Documentos_PDF/ rec1final.pdf>. Acessado em 09/10/2018. 
MINISTÉRIO PÚBLICO DO TRABALHO (Brasilia). Nota técnica $\mathbf{n}^{\circ} \mathbf{0 8}$ de 26 de junho de 2017 da secretaria de relações institucionais do Ministério Publico do Trabalho (MPT) Disponível em: <http://portal.mpt. mp.br/wps/wcm/connect/portal_mpt/ce4b9848-f7e4- 47378d816b3c6470e4 ad/Nota+t\%C3\%A9cnica+n\%C2\%BA+8.2017.pdf?MOD=AJPE RES\&CVID=lPCHY69 > . Acessado em 10/10/2018. 